University of Wisconsin Milwaukee

UWM Digital Commons

Geography Faculty Articles

Geography

$4-5-2018$

\title{
Meteorological and Streamflow Droughts: Characteristics, Trends and Propagation in the Milwaukee River Basin
}

\author{
Woonsup Choi \\ University of Wisconsin - Milwaukee, choiw@uwm.edu \\ Hi-Ryong Byun \\ Claudio Cassardo \\ Jinmu Choi
}

Follow this and additional works at: https://dc.uwm.edu/geog_facart

Part of the Geography Commons

\section{Recommended Citation}

Choi, Woonsup; Byun, Hi-Ryong; Cassardo, Claudio; and Choi, Jinmu, "Meteorological and Streamflow Droughts: Characteristics, Trends and Propagation in the Milwaukee River Basin" (2018). Geography Faculty Articles. 8.

https://dc.uwm.edu/geog_facart/8

This Article is brought to you for free and open access by UWM Digital Commons. It has been accepted for inclusion in Geography Faculty Articles by an authorized administrator of UWM Digital Commons. For more information, please contact open-access@uwm.edu. 
1. Meteorological and Streamflow

2 Droughts: Characteristics, Trends and

3 Propagation in the Milwaukee River

4 Basin

5 Woonsup Choi (D), Hi-Ryong Byun, Claudio Cassardo \& Jinmu

6 Choi

7

8

This is an Accepted Manuscript of an article published by Taylor \& Francis Group in The Professional Geographer on 05/Apr/2018, available online:

https://doi.org/10.1080/00330124.2018.1432368

\section{Abstract}

14 This study examined meteorological and streamflow droughts for the period 1951-2006

15 using the Milwaukee River basin in Wisconsin as the study area in an effort to improve the

16 understanding of drought propagation. Specifically, this study aimed to answer the

17 following research questions: (1) What are the temporal trends of meteorological and

18 streamflow droughts identified by drought indicators? (2) How do the drought indicators

19 manifest drought propagation? Meteorological droughts were identified using the Effective

20 Drought Index (EDI), and streamflow droughts were identified using a threshold-level

21 approach. The intensity and duration of both types of drought were found to have decreased 
22 over time most likely due to increasing precipitation. Therefore, in the study area, and

23 likely in the larger region, drought has become of less concern. The propagation of

24 meteorological drought into streamflow drought was detected generally after moderate and

25 severe sequences of negative EDI that eventually led to extreme meteorological drought

26 events. The study finds that both EDI and the threshold-level approach are effective in

27 diagnosing meteorological and streamflow drought events of all durations.

28

29

30 Keywords: drought index, drought propagation, hydrological drought, meteorological

31 drought, runoff

32 
33 Droughts are causing alarming concern worldwide as they can cripple agricultural 34 production, reduce the availability of drinking water, and harm ecosystems and wildlife. 35 Syria is a good example of how a drought, combined with other factors, may even contribute to a civil war (Kelley et al. 2015). Due to diverse hydrometeorological variables and socioeconomic factors involved, there are a multitude of drought definitions (Mishra and Singh 2010). Meteorological droughts are defined in terms of the magnitude and duration of a precipitation shortfall (AMS 2013), and they can develop into other types of droughts as the precipitation shortage propagates through the hydrological system, such as soil moisture, streamflow, and groundwater (Feyen and Dankers 2009, Mishra and Singh 2010, Van Loon 2015). Deficits of soil moisture and surface/subsurface water against the seasonal normal are known as agricultural and hydrological droughts, respectively (Van Loon 2015). Meteorological droughts begin with anomalous atmospheric conditions, but the ensuing development of soil moisture and hydrological droughts also depends on terrestrial conditions such as land cover, water storage, and runoff pathways (Van Loon 2015). Identification of the relationship between meteorological and hydrological droughts is a relatively recent research agenda (Van Loon 2015), and it has the potential to be helpful for hydrological drought monitoring and early warning (Zhao et al. 2014). Because the propagation of meteorological drought to hydrological drought depends on terrestrial conditions, such research tends to be location-specific.

Drought indicators are used to quantify the magnitude and duration of drought events. Numerous indicators (>100 according to Lloyd-Hughes (2014)) have been proposed for different types of drought and require different variables to calculate. For meteorological drought, popular indicators include the Palmer Drought Severity Index 
56 (PDSI), the Standardized Precipitation Index (SPI) and its variants, and the Effective 57 Drought Index (EDI) among others (for details, see Shelton 2009). Such drought indices measure departure from the mean in standardized forms, and the index values are classified for different levels of drought intensity. For hydrological drought, the threshold-level approach (originally proposed by Yevyevich (1967)) and the Standardized Runoff Index, a standardized index like SPI, are widely used. In the threshold-level approach, the variable of interest is considered to be in a drought condition when it falls below the predetermined threshold. Because the magnitude and duration of drought events are defined based on drought indicators, examining drought propagation involves using such indicators. For example, indicators for meteorological and hydrological droughts are correlated at different time scales such as one month, three months, six months, etc. (e.g. Liu et al. 2012, LorenzoLacruz et al. 2013, Rahiz and New 2014, Zeng et al. 2015, Barker et al. 2016, Zhao, Wu, and Fang 2016). Because droughts develop slowly, monthly scales can be sufficient; however, droughts can terminate abruptly with a large rainfall event or last for a short period, which can be difficult to detect with monthly-scale indices (Byun et al. 2008). Therefore, it is necessary to examine drought at finer scales using indicators that work at such scales. In addition, we find it necessary to examine how often and how soon individual meteorological drought events lead to streamflow drought events. Once a meteorological drought begins, questions may arise regarding whether and when a streamflow drought will begin.

When it comes to the location of drought, those occurring in California or the Great Plains receive much of the attention of the research community in the United States. However, the Midwest's agricultural and industrial activities are also highly influenced by 


\section{$91 \quad$ Study area}

92

drought. For example, corn and soybean yields in some Midwestern states show increasing sensitivity to drought (Lobell et al. 2014).

In this study, we selected a river basin in a Midwestern state to analyze both meteorological and streamflow droughts to examine the following research questions: (1)

What are temporal trends of meteorological and streamflow droughts identified by drought indicators? (2) How do drought indicators manifest drought propagation? We diagnosed meteorological and streamflow droughts using daily-scale drought indicators for a 56-year period and examined precipitation and the indicators of meteorological and streamflow droughts in detail for a two-year period when both strong meteorological and streamflow droughts occurred. Our findings reveal the general trend of drought for the region, shed light on drought propagation, and provide a gauge of the usefulness of the selected methods for diagnosing drought.

The Milwaukee River basin (Fig 1; US Geological Survey Hydrological Unit Code 04040003) was selected mainly due to the lengthy streamflow record and its importance as a habitat for a wide range of plants and animals (http://dnr.wi.gov/water/basin/milw/, last accessed 17 November 2016). The Milwaukee River basin has an area of approximately $2330 \mathrm{~km}^{2}$ and a population of about 1 million. It is nested in the Lake Michigan basin. The topography of the basin consists of rolling moraine over bedrock, sloping downward mostly from northwest to southeast, and the elevation ranges from 177 to $415 \mathrm{~m}$ above sea level (Wisconsin Department of Natural Resources 2001). The basin has three major 
101 rivers, namely Milwaukee, Menomonee, and Kinnickinnic, which merge just before the 102 outlet of the basin.

103 The Milwaukee River basin is divided into six catchments by the Wisconsin 104 Department of Natural Resources: Cedar Creek, East and West Branches Milwaukee River, 105 Kinnickinnic River, Menomonee River, Milwaukee River South, and North Branch 106 Milwaukee River (http://dnr.wi.gov/water/basin/milw/, last accessed 23 December 2015;

107 Fig 1). The Milwaukee River and its tributaries drain four catchments (Cedar Creek, East 108 and West Branches, Milwaukee South, and North Branch). Regarding land cover, 109 Kinnickinnic and Menomonee are most urbanized followed by Milwaukee South, and the 110 remaining three catchments have mostly non-urban land covers (Choi et al. 2016). 111 Kinnickinnic receives the most annual precipitation (Table 1) with $841 \mathrm{~mm}$, followed by 112 North Branch $(818 \mathrm{~mm})$. Precipitation for other catchments is quite similar to that for North 113 Branch. Given the large interannual variability and the similar rainfall in the six catchments, 114 the catchments do not have significantly different annual precipitation.

115 The study region has warm, humid summers and cold winters (Fig 2). Precipitation 116 is large from April to September, exceeding $70 \mathrm{~mm} / \mathrm{month}$. Mean monthly temperature 117 exceeds $20^{\circ} \mathrm{C}$ in July and August and falls to $-4^{\circ} \mathrm{C}$ or lower in December, January, and 118 February.

\section{Meteorological drought determination}

121 Of the popular indicators for meteorological drought mentioned previously, we chose EDI

122 for this study. PDSI is complex to calculate and requires insufficiently measured variables 
123 (e.g., evaporation). SPI requires only precipitation, but measures the departure of 124 precipitation for different accumulation periods (e.g., 3-month, 6-month, etc.). Therefore, 125 if a three-month accumulation period is selected (i.e., SPI-3), SPI-3 does not account for 126 precipitation that occurred more than three months before present. Consequently, it is 127 possible that SPI-3 indicates a drought whereas SPI-4 does not. Unlike PDSI and SPI, EDI 128 explicitly takes the time of precipitation into account, giving more weight to more recent 129 precipitation than to earlier precipitation. EDI works at the daily scale and requires only 130 precipitation.

131 EDI was calculated using the following equations (Byun and Wilhite 1999):

$134 E P_{i}=\left[\frac{\left(\sum_{m=1}^{n} P_{m}\right)}{n}\right]$ (Equation 1)

$137 \quad E D I=\frac{D E P}{S T(D E P)}$

139 where $P_{m}$ is the precipitation for $m$ days before a particular date, $n$ is a dummy index 140 denoting the duration of preceding period, and $i$ is the duration of aggregate precipitation. 141 MEP is the mean of the EP over a 30-year period for the calendar day, and DEP is the 142 deviation from EP, showing the deficiency or surplus of water resources for the date. EDI 143 is computed by dividing DEP by the standard deviation of DEP. 

precipitation over a year's period. As a result, $E P_{365}$, which is the effective precipitation

146 over the last 365 days from the date, is given by:

where the denominator of each term corresponds to $n$. It indicates the aggregate precipitation over a year discounted by time, based on the premise that precipitation in the near past is more important than that in the distant past to understanding conditions in current water resources. negative and positive, $i_{2}$ returns to 365 . The resulting negative EDI values express the standardized deficiency, and positive values express the standardized surplus of water resources stored over many years, respectively.

This study used a daily historical gridded precipitation dataset covering the whole of Wisconsin. It was produced by spatially interpolating weather-station data across the 161 state and available for 1950-2006 with 8-km grid spacing (Serbin and Kucharik 2009). As 162 shown in Fig 1, each catchment contains several grid points, thus the spatial resolution of 163 the data is deemed adequate for the analysis. The grid points falling in the Milwaukee River 164 basin were selected, and the precipitation data were spatially averaged for each of the six 165 catchments to calculate EDI. Therefore, the study did not take full advantage of the high 166 spatial resolution of the precipitation data. Precipitation was averaged for each catchment 
167 in part because the spatial variability of precipitation was not large and in part because the 168 study focused on the correspondence between meteorological and streamflow droughts.

169 Wet and dry days were similar among the grid points for each catchment, therefore 170 averaging did not significantly influence the wet-dry sequences. Total annual precipitation 171 averaged for each catchment is presented in Table 1. The first year's data cannot produce 172 the same year's EDI, thus EDI was calculated for the years 1951-2006. Examples of meteorological droughts identified by EDI are shown in Fig 3a for a 174 hypothetical year. In the graph, days with positive EDI are wet periods and those below 175 zero are dry periods. A sequence of days with negative EDI is considered a drought event, 176 and its intensity is determined by the minimum EDI value during that period. Drought 177 intensity was classified (e.g. moderate, severe, and extreme) according to Oh, Byun, and 178 Kim (2014) as shown in Table 2. In Fig 3a, a moderate drought (minimum EDI above -1.5 179 and below -0.7 ) began approximately on Day 5 and ended approximately on Day 70 when 180 EDI turned positive. Another moderate drought occurred approximately from Day 130 to 181 Day 165. An extreme drought event (minimum EDI below -2.5) commenced on 182 approximately Day 180 and continued to the next year. We also examined the temporal trends of annual minimum EDI because the 184 intensity of meteorological drought is classified based on the minimum EDI value of the 185 event. The monotonic trend was analyzed using the Mann-Kendall test for trend, and the 186 periodicity was examined using spectral analysis. The spectral analysis was performed 187 using the function spec.pcgram (https://stat.ethz.ch/R-manual/R$188 \mathrm{devel} /$ library/stats/html/spec.pgram.html) of R software, which calculates the periodogram 
using a fast Fourier transform. To avoid a misinterpretation of the spectra results, the data were initially detrended series by series.

\section{Streamflow drought determination}

We employed the threshold-level approach for streamflow drought. As mentioned before, it was widely adopted for hydrological drought research, particularly for drought propagation (Vrochidou et al. 2013). For the streamflow time-series $x(t)$, the deficit volume (D) below the threshold for a particular drought is calculated as

$$
D=\int_{t_{b}}^{t_{e}}(T-x(t)) d t
$$

where $T$ is an appropriate threshold level, and $t_{b}$ and $t_{e}$ are the start and end date of the drought; thus, drought duration (in days) can be defined as $L=t_{e}-t_{b}$. In accordance with previous studies (e.g. Wong et al. 2011, Van Lanen et al. 2013), we selected the $20^{\text {th }}$ percentile (the value exceeded $80 \%$ of the time) of the streamflow data as the threshold, $T$. Streamflow droughts were determined using the observed streamflow data at the Milwaukee River U.S. Geological Survey (USGS) site (Fig 1). It became operational in 1914 and is located close to the outlet of the Milwaukee South catchment. Therefore, the discharge from Cedar Creek, East and West Branches, and North Branch is part of the streamflow measured here. We analyzed the streamflow data for 1951-2006 to match the EDI data and used 30-day moving means to smooth the daily streamflow data. We also converted the unit of the streamflow data from cubic feet per second to millimeters to 
211 express streamflow as depth over the entire catchment. The Menomonee River site became

212 operational since the 1960s, so its data were used as auxiliaries. Other UGSG sites within

213 the basin were not used in this study because their records are much shorter than the

214 precipitation data. If the study was extended to a larger area, it would be conducted for

215 selected river basins scattered over the region because of the wide range of lengths of

216 operation of streamflow measurement sites.

217 We determined the $20^{\text {th }}$ percentile streamflow values for each calendar day (from 1

218 January to 31 December, excluding 29 February) of the data period, which resulted in a

219 time series of 365 entries. Then we calculated 30-day moving means to smooth the

220 threshold line. The $20^{\text {th }}$ percentile was applied to the daily streamflow series to determine

221 streamflow deficit. Continuous days with below-threshold streamflow constitute a drought

222 event. Drought events lasting three days or less were ignored as in other studies (e.g.

223 Vrochidou et al. 2013). When there is a short non-drought period between two drought

224 events, the two drought events are considered mutually dependent droughts (Fleig et al.

225 2006). In this study, mutually dependent droughts were pooled when the non-drought

226 period between them was shorter than three days. Means of deficit values for the preceding

227 and following days of the non-drought days were assigned to the non-drought days.

228 An example of streamflow drought is illustrated in Fig $3 \mathrm{~b}$ for the same hypothetical

229 year as the meteorological drought examples. Three events are easily visible, and they

230 commenced on approximately Day 145, Day 195, and Day 268. The last event continued

231 to the following year. The solid area below the streamflow line for each event is considered

232 as cumulative deficit of the event. 
Annual minimum EDI showed an increasing trend (Fig 4) for the six catchments $(p<0.01)$.

237 There is only one year with minimum EDI above -0.7 (threshold between normal and 238 moderate drought) before 1980, but several thereafter. The graph also demonstrates the 239 periodicity of annual minimum EDI to some extent. A few years of increase are followed 240 by a few years of decrease. Troughs were found at most catchments with intervals ranging 241 from 2 to 8 years. The EDI calculated from precipitation data measured at the Milwaukee 242 Airport weather station showed a trough in 2012 (not shown), seven years after the trough 243 in 2005. When it comes to minimum EDI below -2.5 (threshold between severe and 244 extreme drought), troughs were found for the years 1958, 1964, 1967, 1970, 1977, 1988, 245 and 1992 for most catchments. precipitation, tended to diverge from other catchments several times. For example, its

249 minimum EDI was much higher than the others in 1955, 1977, and 1996 and much lower 250 in 1964, 1997, and 2003. The catchments diverged from each other to a large extent in the 251 years 1964, 1996, 1998, and 2003. Such results suggest a need for more investigation of 252 the spatial variability of drought, even for a mid-size basin with simple topography.

The significant periodicity, emerging in all six catchments, was the one of 6.67 years, but also periodicities of 4.62 years and 3 years were found in five and four 255 catchments, respectively. An example is presented in Fig 5 for Cedar Creek. The lowest 
256 minima in several series are observed in the years 1958 and 1964 (Fig 4), which are

257 separated by 6 years. In other periods, shorter periodicities ( 3 and 4.62 years) are also

258 evident, especially in the most recent years. Therefore, the region needs to prepare for

259 severe and extreme meteorological drought events every 4-6 years.

260 Characteristics of drought events

262 During 1951-2006, the Milwaukee South catchment had 9 and 21 meteorological drought 263 events (Table 3) classified as extreme and severe, respectively (see Table 2 for 264 classification). More intense droughts tended to occur less frequently and with longer 265 durations. The duration was as short as seven days and many events lasted for less than a 266 month. It indicates the usefulness of EDI in diagnosing both short- and long-duration 267 droughts. The total number of events was 95 (1.7 per annum). According to the 268 classification scheme used for this study, meteorological drought is a phenomenon 269 occurring more than once a year on average. The average frequency of 1.7 per annum is 270 slightly higher than previous studies that used EDI for different regions. For example, Lee 271 et al. (2014) report 75 events for South Korea during 1952-2007 (1.34 per annum), and Oh 272 et al. (2014) report 29-50 events for different subregions of East Asia during 1962-2004 273 (0.7-1.2 per annum). Having more than one drought event per annum sounds incompatible 274 with the general perception that droughts occur every once in a while. We doubt that the 275 moderate drought events identified in this study would be recognized as drought by the 276 general public. The results suggest that only extreme and severe events deserve to be 277 recognized as drought in the study area.

278 Six of the nine meteorological drought events classified as extreme for the 279 Milwaukee South catchment occurred before 1970 (Table 4). The 1950s and 1960s had 
280 three events each, and the 1990s had none. All the extreme drought events lasted at least 281 four months, and the one that began in 1962 lasted for nearly two years. Except for the one 282 that began in November 1967, all the events commenced in spring or summer months. The 283 extreme drought events tended to terminate in late spring and summer when precipitation 284 was generally abundant.

The duration and intensity of streamflow drought generally decreased over time (Fig 6). Here intensity is represented by the deficit below the threshold (in $\mathrm{mm}$ ) which 287 indicates the depth of water evenly spread over the basin, not just the river. Each bar in the graph represents an individual event sorted by time. Upward bars indicate duration and downward bars deficit of the event. There were 58 events during 1951-2006 ( 1 per annum). When averaged, it looks as if drought occurred almost every year, but the occurrences are unevenly distributed (see Fig 7). Fig 7 suggests that even after pooling of 292 mutually dependent droughts, some events still were counted separately. We found a median duration of 17 days, a median deficit of $0.37 \mathrm{~mm}$, and a strong correlation between 294 the deficit and the duration $(r<-0.7 ; p<0.05)$. The results are similar for the Menomonee 295 River site (not shown). Its median duration was 22 days and median deficit was $2.25 \mathrm{~mm}$. 296 The Menomonee catchment is much more urbanized than the Milwaukee and its upstream 297 catchments, and their streamflow characteristics appear to manifest it.

299 previous studies that used the threshold approach. For example, Vrochidou et al. (2013) 300 report 23 streamflow drought events during 1974-1999 (0.88 per annum) for a Greek basin 301 using the $20^{\text {th }}$ percentile threshold, and Liu et al. (2016) report 27 events using the $30^{\text {th }}$ 302 percentile monthly threshold during 1980-2009 for a northern Chinese basin (0.9 per 
303 annum). Because streamflow drought was defined using pre-determined thresholds, 304 drought-like conditions, regardless of duration or severity, may have been left uncounted.

305 This limitation applies to virtually all studies diagnosing drought quantitatively, and we are 306 not aware of any reasonable alternatives.

307

308

\section{Drought time series}

Meteorological droughts appeared to be quite common and severe in the 1950s and 1960s and much less so in the 1980s and 1990s (Fig 8). Droughts somewhat rebounded in the 2000s, with multiple events with minimum EDI values below -1.5 during 2000-2006. Similar trends are reported for nearby states of Illinois and Indiana (Mishra, Cherkauer, and Shukla 2010), suggesting a regional-scale phenomenon. Annual total precipitation increased in the Milwaukee area during the time with varying degrees and levels of confidence (Kucharik et al. 2010, Keuser 2014, Choi et al. 2016), to which the meteorological drought trend is attributable. An abrupt termination of drought was also found in the graph in the middle of September 1961. An exceptionally large rainfall event ( $>120 \mathrm{~mm}$ during 15-17 September) helped abruptly push the EDI value above zero. This would not have been detected with monthly-scale indices such as SPI or PSDI. Similar results were found for Menomonee (not shown).

Streamflow droughts were much less frequently observed after the 1970s (Fig 7).

Only three events were observed during the 1980s, two during the 1990s, and slightly more in the 2000s, reflecting the meteorological droughts. The reduced occurrence of streamflow droughts since the 1970s is also found in another study for several Midwestern states, and such changes suggest that the long term (decadal or longer) process in the atmospheric general circulation somewhat changed after the 1970s (Changnon 1996). It should be noted 
327 that the Milwaukee River basin was not included in that study, and streamflow drought was 328 determined differently from this study. Compared with the EDI time series (Fig 8), the 329 streamflow deficit time series appeared to hide many minor events that did not exceed the 330 threshold. During the 1980s and 1990s, several severe meteorological drought events were 331 identified, but very few streamflow drought events were identified according to the $20^{\text {th }}$ 332 percentile threshold. This is due to the inherent difference between a standardized-index 333 approach like EDI and a threshold approach. If streamflow remained quite low for a while 334 but above the threshold, it would not count as a drought event. On the other hand, a 335 to streamflow drought events in Fig 7 with varying lag times. For example, the extreme 341 meteorological drought for Milwaukee South that commenced on 16 August 1953 is 342 followed by a streamflow drought from 31 August, which lasted for 157 days. The extreme meteorological drought events in 2003 for Milwaukee South were followed by streamflow 344 droughts in late August with a lag of about ten weeks. On the other hand, a fairly significant 345 streamflow drought occurred in the spring of 2003, but it was preceded by a severe, though 346 not extreme, meteorological drought from November 2002 (see Fig 8). Actually, the year 3472003 was in a meteorological drought condition for most of the year with only days 348 separating different events (see Fig 8). Despite that, streamflow drought was not 349 remarkable, particuarly in the second half of the year. 
The propagation of meteorological drought to streamflow drought for the

351 Milwaukee River USGS site is portrayed in Fig 9 for the years 1976-1977. An unusual

352 statewide agricultural drought occurred in 1976 (Mitchell 1979), and an emergency was

353 declared by Federal Emergency Management Agency on 17 June 1976. During this period,

354 an extreme meteorological drought event commenced and terminated (Table 4). In Fig 9,

355 daily precipitation (top panel) is shown with mean daily precipitation during the record

356 period. Precipitation was generally below the average from late May of 1976 through

357 February of 1977 and was quite abundant in 1977. After briefly falling below zero in mid-

358 June, EDI remained below zero continuously from late June of 1976 through late July of

359 1977. A few large rainfall events in the summer of 1976 brought EDI close to but still 360 below zero in August 1976. Precipitation was abundant in April 1977 as well and brought

361 EDI up again, but EDI still remained below zero. EDI began to fluctuate around zero from

362 late July due to the abundant summer precipitation and remained positive for the rest of the 363 year from September 1977. Streamflow drought became evident only in September 1976, 364 whereas EDI was negative from late June. There was a short (lasting six days) streamflow 365 drought in July with a very small deficit. Streamflow drought disappeared in late February 3661977 when EDI began to increase. From April to May 1977, streamflow drought was very 367 intense in response to falling EDI. The drought terminated at the beginning of June 1977. 368 Similar results were found for Menomonee (not shown).

369 The intense streamflow drought in May 1977 contrasted with the longer and less 370 intense event during the winter of $1976-1977$. The $20^{\text {th }}$ percentile threshold is much lower 371 in magnitude during the winter than in May. Because winter is a low flow season, the room 372 for streamflow deficit is quite small. In May, much more flow is expected than in January 
373 or February. Even though the absolute flow level in May 1977 was larger than that of the 374 winter of 1976-1977, the deficit was much larger, making the drought even more intense. 375 After June 1977, the streamflow drought was no longer observed with increasing 376 streamflow and decreasing threshold.

\section{Conclusions}

379 We examined meteorological and streamflow droughts for the period 1951-2006 for the 380 Milwaukee River basin in Wisconsin in an effort to improve the understanding of drought 381 propagation. Specifically, we aimed to answer the following research questions: (1) What 382 are the temporal trends of meteorological and streamflow droughts identified by drought 383 indicators? (2) How do the drought indicators manifest drought propagation? We employed 384 the Effective Drought Index and the threshold-level approach for diagnosing 385 meteorological and streamflow drought events, respectively. In addition, we examined in 386 detail daily time series of precipitation and drought indicators for a two-year period of $387 \quad$ 1976-1977 that saw significant drought events.

388 In conclusion, the magnitude and duration of drought generally decreased during 389 the 56-year period in the study area most likely due to increasing precipitation. Therefore, 390 in the study area and likely in the larger region, drought has become increasingly less of a 391 concern. With respect to the propagation of meteorological drought to streamflow drought, 392 streamflow droughts were detected generally after moderate and severe sequences of 393 below-normal precipitation that eventually led to extreme meteorological drought events. 394 Streamflow was generally responsive to precipitation events but it took sustained 
395 precipitation shortage from days to weeks for streamflow drought to manifest itself. 396 Termination of streamflow drought in this approach accompanied large rainfall events.

397 However, the termination of streamflow drought does not mean that water is available at a 398 normal level but rather that water recovery just has commenced.

399 
400

401

402

403

404

405

406

407

408

409

410

411

412

413

414

415

416

417

418

419

420

421

422

\section{References}

AMS. Drought: An Information Statement of the American Meteorological Society. In American Meteorological Society [database online]. 2013 Available from https://www.ametsoc.org/POLICY/2013drought_amsstatement.pdf (last accessed Oct 1 2014).

Barker, L. J., J. Hannaford, A. Chiverton, and C. Svensson. 2016. From meteorological to hydrological drought using standardised indicators. Hydrology and Earth System Sciences 20:2483-2505.

Byun, H., and D. Wilhite. 1999. Objective Quantification of Drought Severity and Duration. Journal of Climate 12:2747-2756.

Byun, H., S. Lee, S. Morid, K. Choi, S. Lee, and D. Kim. 2008. Study on the Periodicities of Droughts in Korea. Asia-Pacific Journal of Atmospheric Sciences 44:417-441.

Changnon, D. 1996. Changing temporal and spatial characteristics of Midwestern hydrologic droughts. Physical Geography 17:29-46.

Choi, W., K. Nauth, J. Choi, and S. Becker. 2016. Urbanization and Rainfall-Runoff Relationships in the Milwaukee River Basin. The Professional Geographer 68:1425.

Feyen, L., and R. Dankers. 2009. Impact of global warming on streamflow drought in Europe. Journal of Geophysical Research-Atmospheres 114:D17116.

Fleig, A. K., L. M. Tallaksen, H. Hisdal, and S. Demuth. 2006. A global evaluation of streamflow drought characteristics. Hydrology and Earth System Sciences 10:535552. 
Kelley, C. P., S. Mohtadi, M. A. Cane, R. Seager, and Y. Kushnir. 2015. Climate change in the Fertile Crescent and implications of the recent Syrian drought. Proceedings of the National Academy of Sciences 112:3241-3246.

Keuser, A. P. M. 2014. Precipitation Patterns and Trends in the Metropolitan Area of Milwaukee, Wisconsin. International Journal of Geospatial and Environmental Research 1(1):Article 6. (http://dc.uwm.edu/ijger/vol1/iss1/6)

Kucharik, C. J., S. P. Serbin, S. Vavrus, E. J. Hopkins, and M. M. Motew. 2010. Patterns of Climate Change Across Wisconsin from 1950 to 2006. Physical Geography 31:128.

Lee, B., S. Oh, and H. Byun. 2014. The characteristics of drought occurrence in North Korea and its comparison with drought in South Korea. Theoretical and Applied Climatology 121:199-209.

Liu, L., Y. Hong, C. Bednarczyk, B. Yong, M. Shafer, R. Riley, and J. Hocker. 2012. Hydro-Climatological Drought Analyses and Projections Using Meteorological and Hydrological Drought Indices: A Case Study in Blue River Basin, Oklahoma. Water Resources Management 26:2761-2779.

Liu, Y., L. Ren, Y. Zhu, X. Yang, F. Yuan, S. Jiang, and M. Ma. 2016. Evolution of Hydrological Drought in Human Disturbed Areas: A Case Study in the Laohahe Catchment, Northern China. Advances in Meteorology5102568.

Lloyd-Hughes, B. 2014. The impracticality of a universal drought definition. Theoretical and Applied Climatology 117:607-611. 
444 Lobell, D. B., M. J. Roberts, W. Schlenker, N. Braun, B. B. Little, R. M. Rejesus, and G.

445 L. Hammer. 2014. Greater Sensitivity to Drought Accompanies Maize Yield

$446 \quad$ Increase in the U.S. Midwest. Science 344:516-519.

447 Lorenzo-Lacruz, J., S. M. Vicente-Serrano, J. C. Gonzalez-Hidalgo, J. I. Lopez-Moreno,

448 and N. Cortesi. 2013. Hydrological drought response to meteorological drought in

$449 \quad$ the Iberian Peninsula. Climate Research 58:117-131.

450 Mishra, A. K., and V. P. Singh. 2010. A review of drought concepts. Journal of

$451 \quad$ Hydrology 391:202-216.

452 Mishra, V., K. A. Cherkauer, and S. Shukla. 2010. Assessment of Drought due to Historic

453 Climate Variability and Projected Future Climate Change in the Midwestern United

$454 \quad$ States. Journal of Hydrometeorology 11:46-68.

455 Mitchell, V. L. 1979. Drought in Wisconsin. Wisconsin Academy of Sciences, Arts and

$456 \quad$ Letters 67:130-134.

457 Oh, S., H. Byun, and D. Kim. 2014. Spatiotemporal characteristics of regional drought

$458 \quad$ occurrence in East Asia. Theoretical and Applied Climatology 117:89-101.

459 Rahiz, M., and M. New. 2014. Does a rainfall-based drought index simulate hydrological

$460 \quad$ droughts? International Journal of Climatology 34:2853-2871.

461 Serbin, S. P., and C. J. Kucharik. 2009. Spatiotemporal Mapping of Temperature and

462 Precipitation for the Development of a Multidecadal Climatic Dataset for Wisconsin.

$463 \quad$ Journal of Applied Meteorology and Climatology 48:742-757.

464 Shelton, M. L. 2009. Hydroclimatology: Perspectives and Applications. Cambridge

$465 \quad$ University Press. 
Van Lanen, H. A. J., N. Wanders, L. M. Tallaksen, and A. F. Van Loon. 2013. Hydrological drought across the world: impact of climate and physical catchment structure. Hydrology and Earth System Sciences 17:1715-1732.

Van Loon, A. F. 2015. Hydrological drought explained. Wiley Interdisciplinary ReviewsWater 2:359-392.

Vrochidou, A. -. K., I. K. Tsanis, M. G. Grillakis, and A. G. Koutroulis. 2013. The impact of climate change on hydrometeorological droughts at a basin scale. Journal of Hydrology 476:290-301.

Wisconsin Department of Natural Resources. 2001. The State of the Milwaukee River Basin. Madison, Wisconsin: Wisconsin Department of Natural Resources, Report Number, PUBL WT 7042001.

Wong, W. K., S. Beldring, T. Engen-Skaugen, I. Haddeland, and H. Hisdal. 2011. Climate Change Effects on Spatiotemporal Patterns of Hydroclimatological Summer Droughts in Norway. Journal of Hydrometeorology 12:1205-1220.

Yevyevich, V. 1967. An Objective Approach to Definition and Investigations of Continental Hydrologic Droughts. Hydrology Papers, Colorado State University 23.

Zeng, X., N. Zhao, H. Sun, L. Ye, and J. Zhai. 2015. Changes and Relationships of Climatic and Hydrological Droughts in the Jialing River Basin, China. PLoS ONE 10:e141648.

Zhao, L., Lyu Aifeng, Wu Jianjun, M. Hayes, Tang Zhenghong, He Bin, Liu Jinghui, and Liu Ming. 2014. Impact of meteorological drought on streamflow drought in Jinghe River Basin of China. Chinese Geographical Science 24:694-705. 
488 Zhao, L., J. Wu, and J. Fang. 2016. Robust Response of Streamflow Drought to Different 489 Timescales of Meteorological Drought in Xiangjiang River Basin of China. $490 \quad$ Advances in Meteorology1634787.

491 


\section{Tables}

Table 1. Selected information on the six catchments of the Milwaukee River basin. The coordinates are means of the climate data grid points falling in the basin. The mean annual precipitation is for the period 1950-2006 and shown with \pm standard deviation of annual total precipitation.

\begin{tabular}{llll}
\hline $\begin{array}{l}\text { Catchment } \\
\text { name }\end{array}$ & Latitude, longitude (d.d.) & $\begin{array}{l}\text { Mean elevation } \\
\text { (m.a.s.1.) }\end{array}$ & $\begin{array}{l}\text { Mean annual } \\
\text { precipitation (mm) }\end{array}$ \\
\hline $\begin{array}{l}\text { Milwaukee } \\
\text { South }\end{array}$ & $43.236,-87.959$ & 223.0 & $809 \pm 123$ \\
Menomonee & $43.125,-88.098$ & 241.4 & $807 \pm 127$ \\
Kinnickinnic & $42.960,-87.889$ & 308.6 & $841 \pm 152$ \\
$\begin{array}{l}\text { East and West } \\
\text { Branches }\end{array}$ & $43.574,-88.223$ & 308.6 & $803 \pm 113$ \\
Cedar Creek & $43.342,-88.131$ & & $809 \pm 120$ \\
North Branch & $43.569,-88.042$ & 281.1 & $818 \pm 122$ \\
\hline
\end{tabular}

Note: d.d. = decimal degrees; m.a.s.l. = meters above sea level

Table 2. Classification of drought intensity by EDI values (Oh, Byun, and Kim 2014)

Effective Drought Index

2.5 or higher

Above 1.5 and below 2.5

Above 0.7 and below 1.5

Above 0 and below 0.7

Above -0.7 and 0

Above -1.5 and below -0.7

Above -2.5 and below -1.5

Below -2.5
Classification

Extremely wet

Severely wet

Moderately wet

Weakly wet (normal)

Weakly dry (normal)

Moderately dry

Severely dry

Extremely dry 
507 Table 3. Summary characteristics of meteorological drought by class for the Milwaukee 508 South catchment

\begin{tabular}{l|c|c|c|c}
\hline \multirow{2}{*}{ Drought class } & \multirow{2}{*}{ Number of events } & \multicolumn{3}{|c}{ Duration (days) } \\
\cline { 3 - 5 } & & Maximum & Median & Minimum \\
\hline Extreme & 9 & 724 & 260 & 120 \\
\hline Severe & 21 & 361 & 157 & 38 \\
\hline Moderate & 65 & 175 & 39 & 13 \\
\hline
\end{tabular}

509

510

511

512

513

514

515

516

517

518

519

520
Table 4. Characteristics of extreme meteorological drought events for the Milwaukee South catchment

\begin{tabular}{llll}
\hline Onset date & Duration (days) & Minimum EDI & Date of minimum EDI \\
\hline 1953 August 16 & 260 & -2.85 & 1954 January 18 \\
1955 July 26 & 286 & -2.58 & 1956 February 11 \\
1957 June 29 & 469 & -3.44 & 1958 August 21 \\
1962 April 17 & 724 & -3.66 & 1964 January 18 \\
1967 July 8 & 120 & -2.6 & 1967 September 14 \\
1967 November 9 & 196 & -2.65 & 1968 April 4 \\
1976 June 29 & 391 & -3.19 & 1977 February 27 \\
1988 May 13 & 142 & -2.54 & 1988 September 10 \\
2003 May 30 & 171 & -2.57 & 2003 September 14 \\
\hline
\end{tabular}



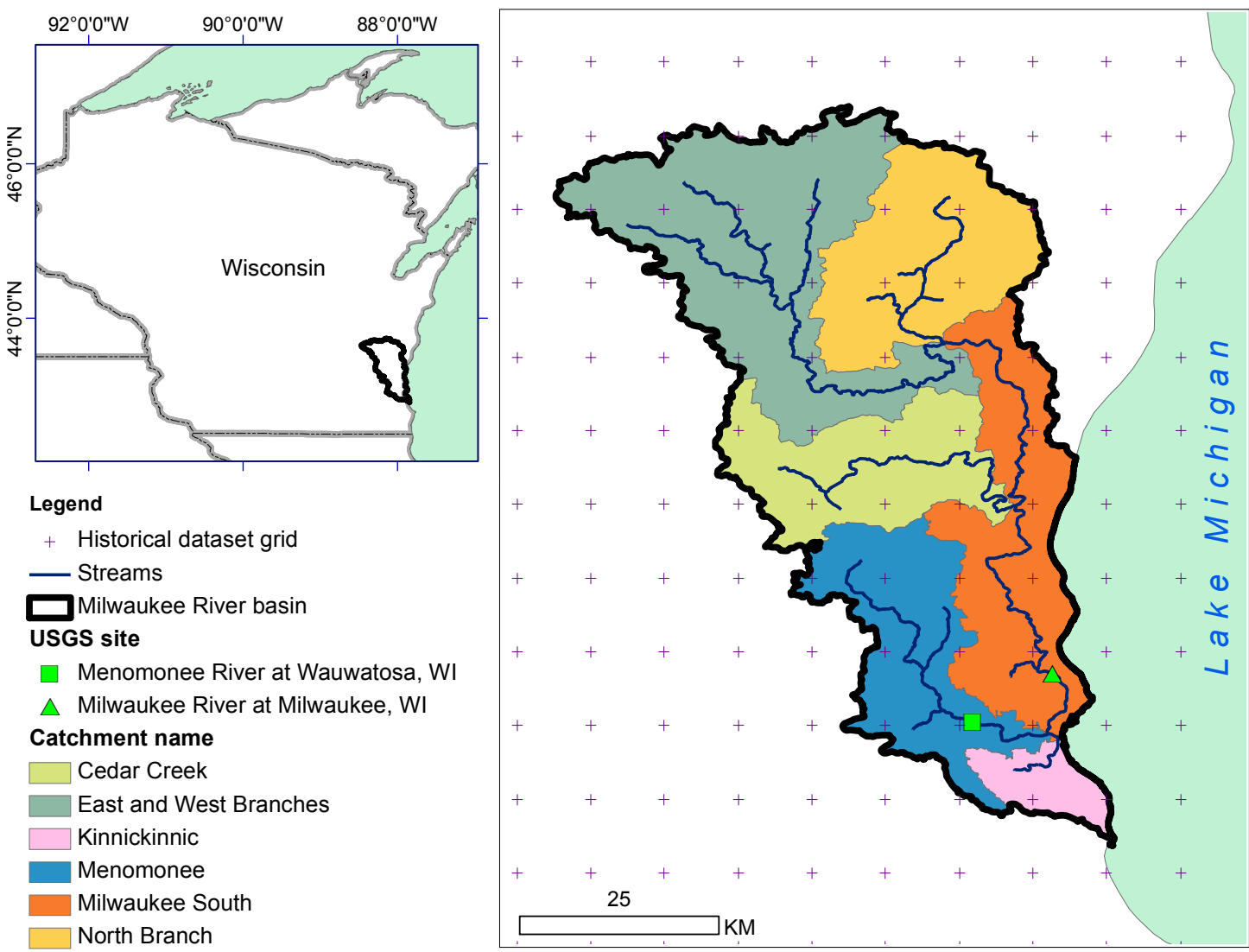

Fig 1 Study area: boundary of the Milwaukee River basin, boundaries of six nested catchments, major streams, grid points of historical precipitation dataset, and the two U.S. Geological Survey (USGS) streamflow measurement sites. 

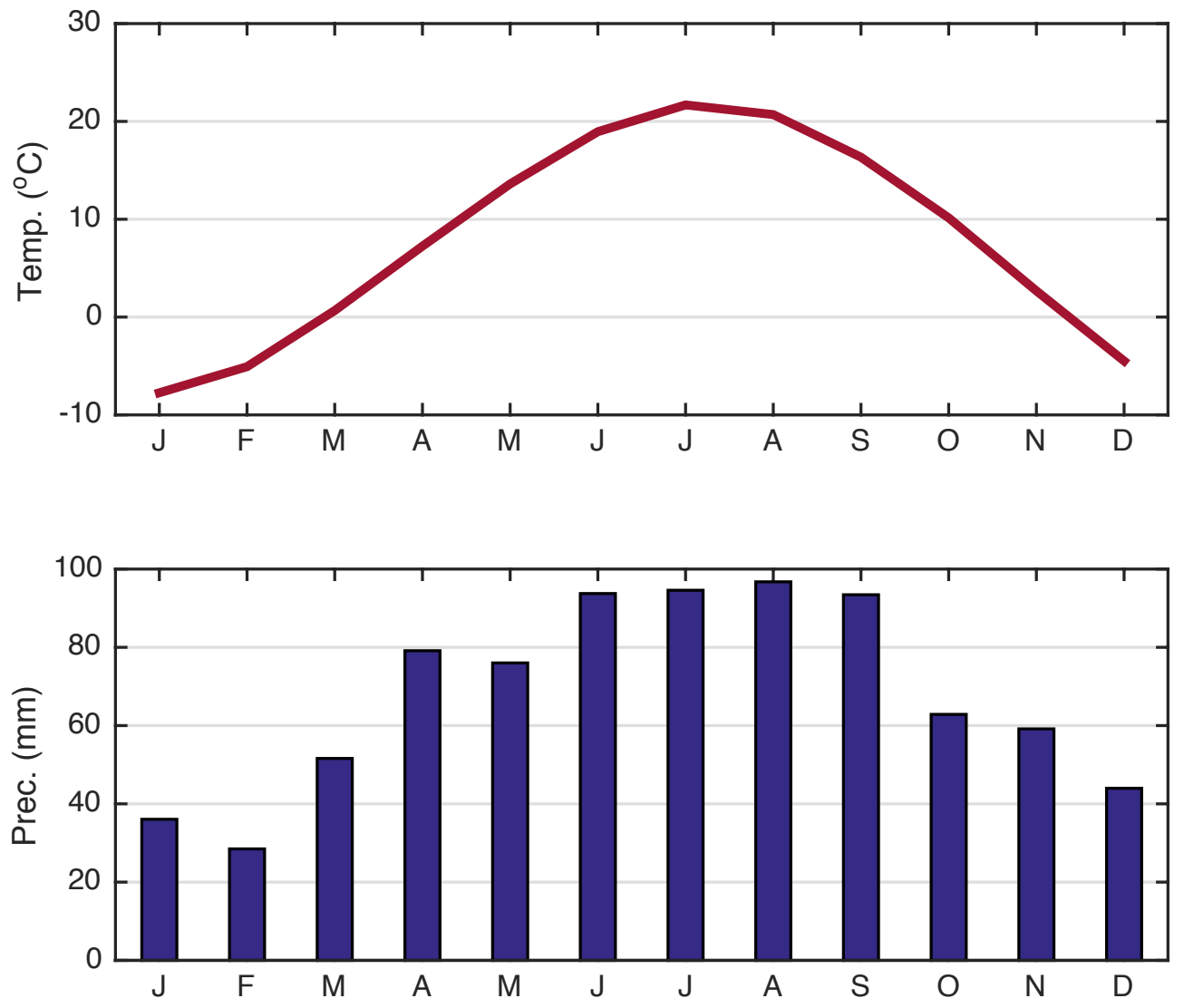

Fig 2 Mean monthly temperature (upper panel) and precipitation (lower panel) for the entire Milwaukee River basin calculated from the historical gridded data (Serbin and Kucharik 2009) 
A)

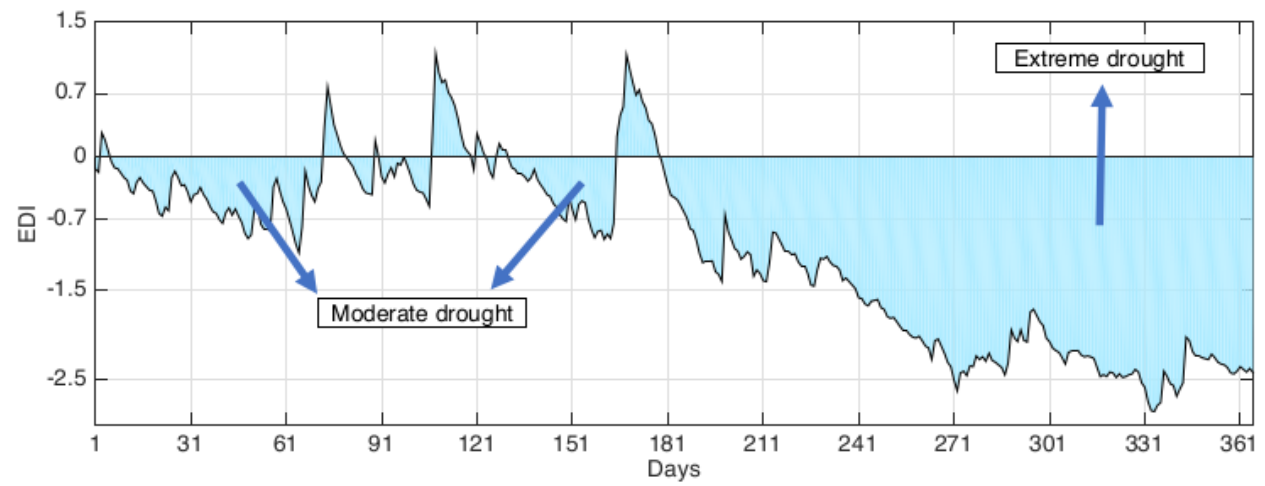

B)

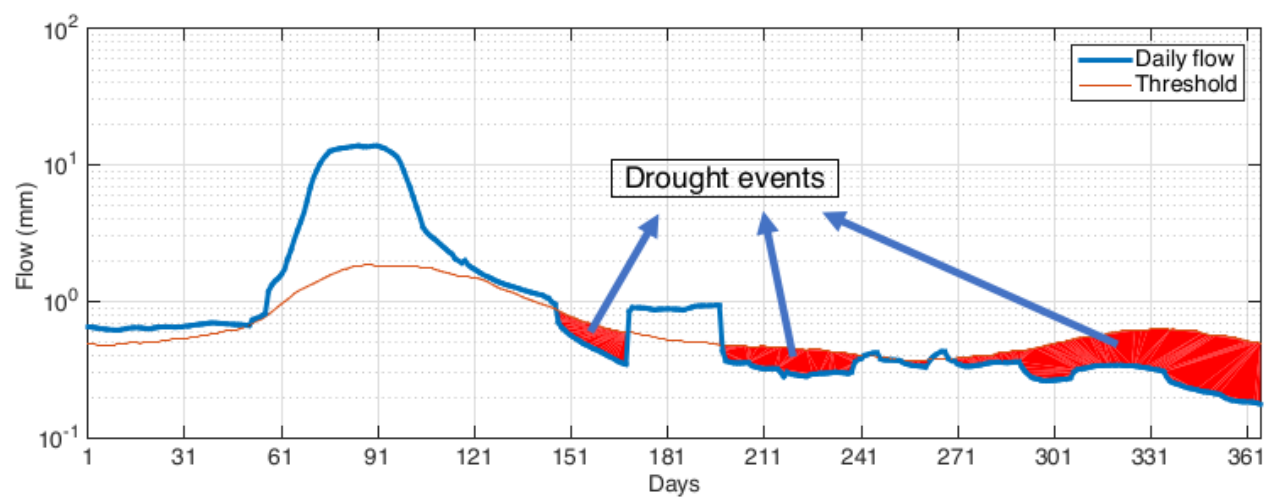

535 Fig 3 Illustration of meteorological drought events (upper panel) and streamflow drought 536 (lower panel) using drought indicators over a one-year period 


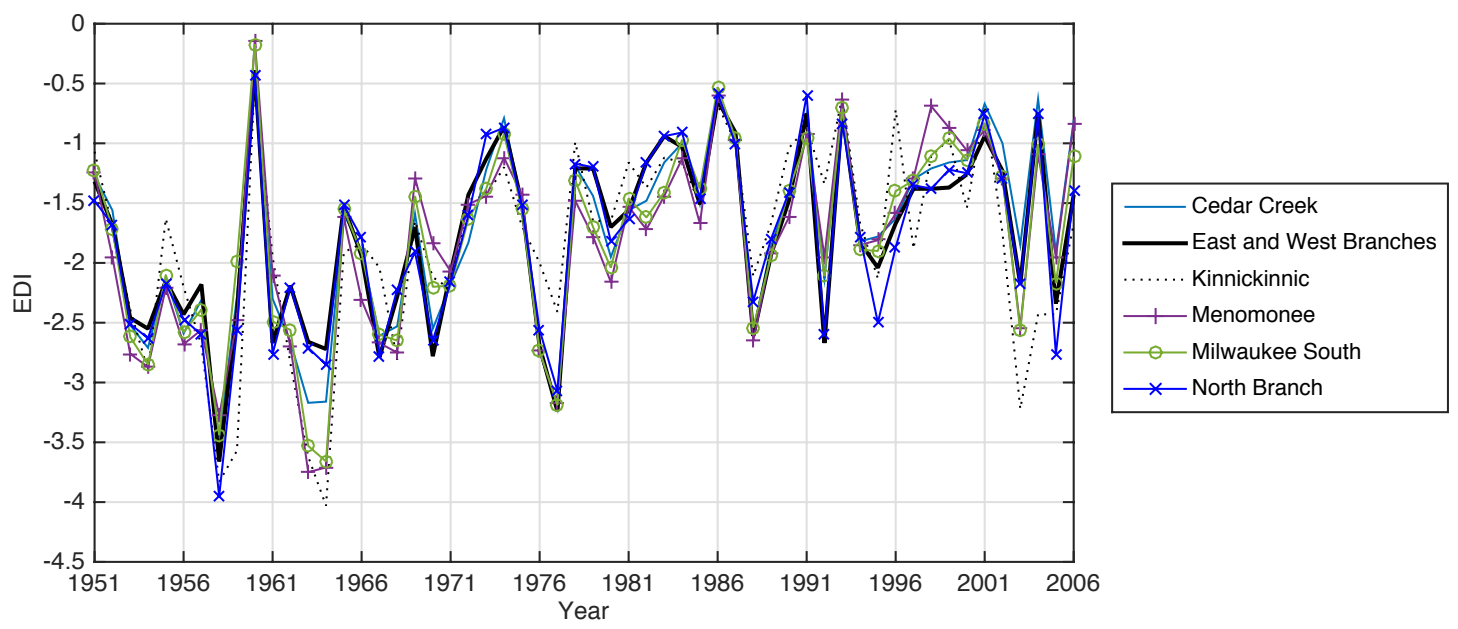

Fig 4 Annual minimum Effective Drought Index series for the six catchments of the Milwaukee River basin 


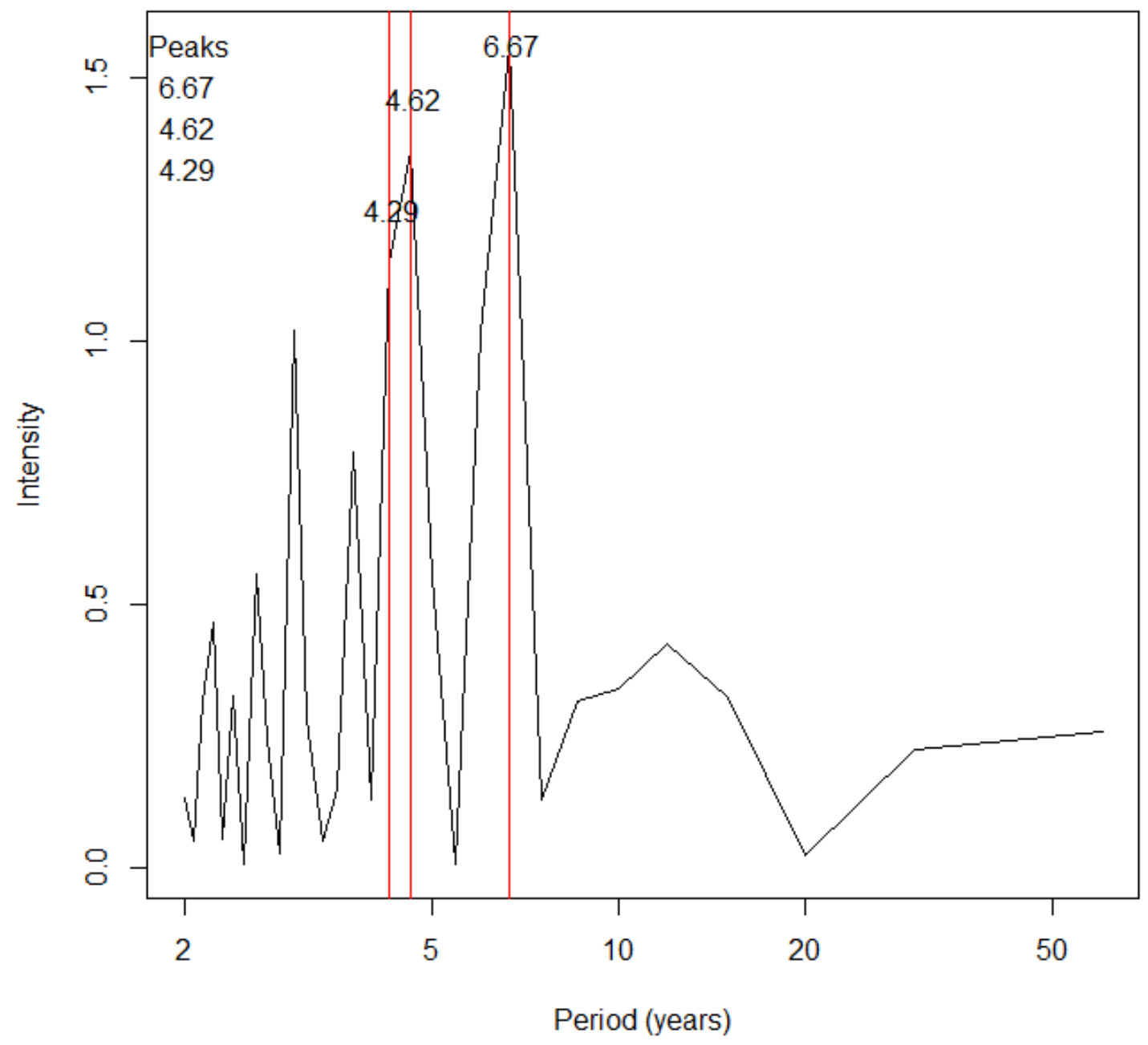

540

541 Fig 5 Spectral analysis of annual minimum Effective Drought Index calculated for Cedar 542 Creek 


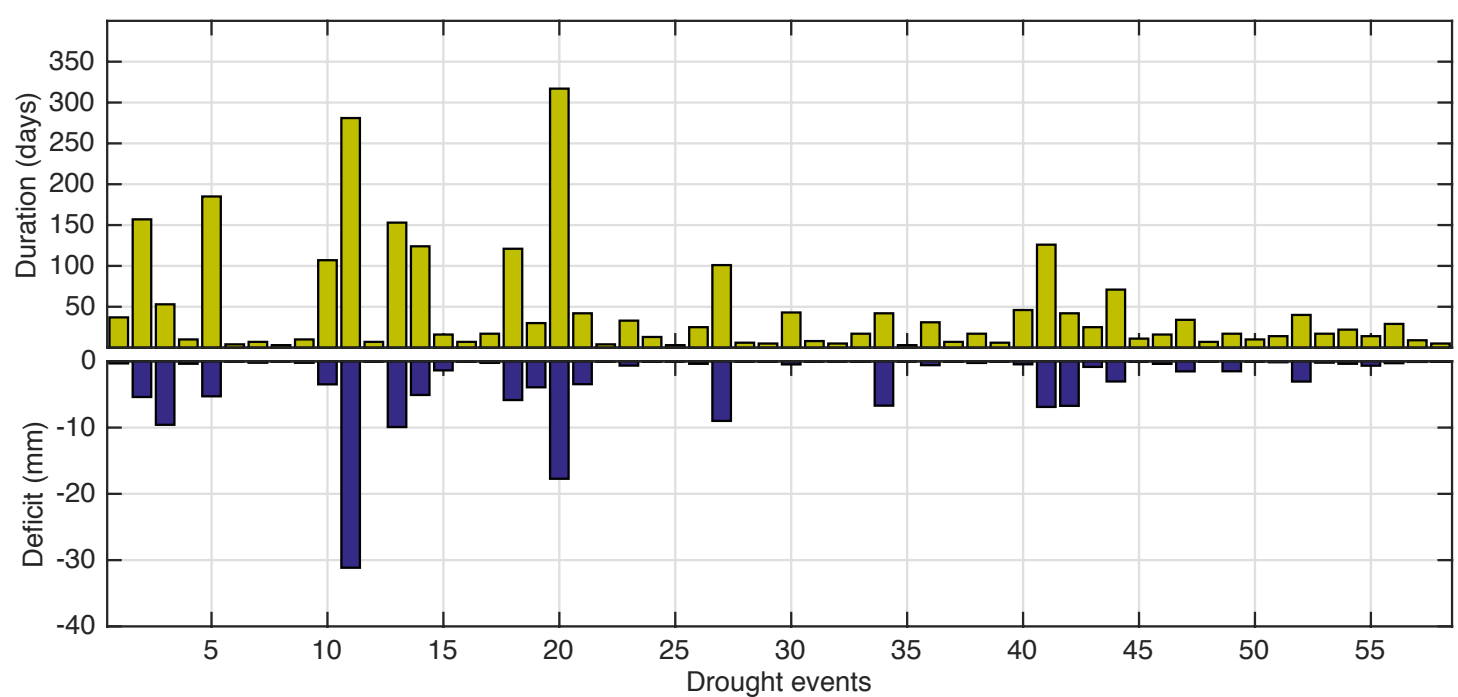

543

544

545

546

Fig 6 Streamflow drought duration (upper panel) and cumulative deficit (lower panel) for each of the 58 events at Milwaukee during 1951-2006. The x-axis indicates each individual event (1: oldest, 58: most recent) 

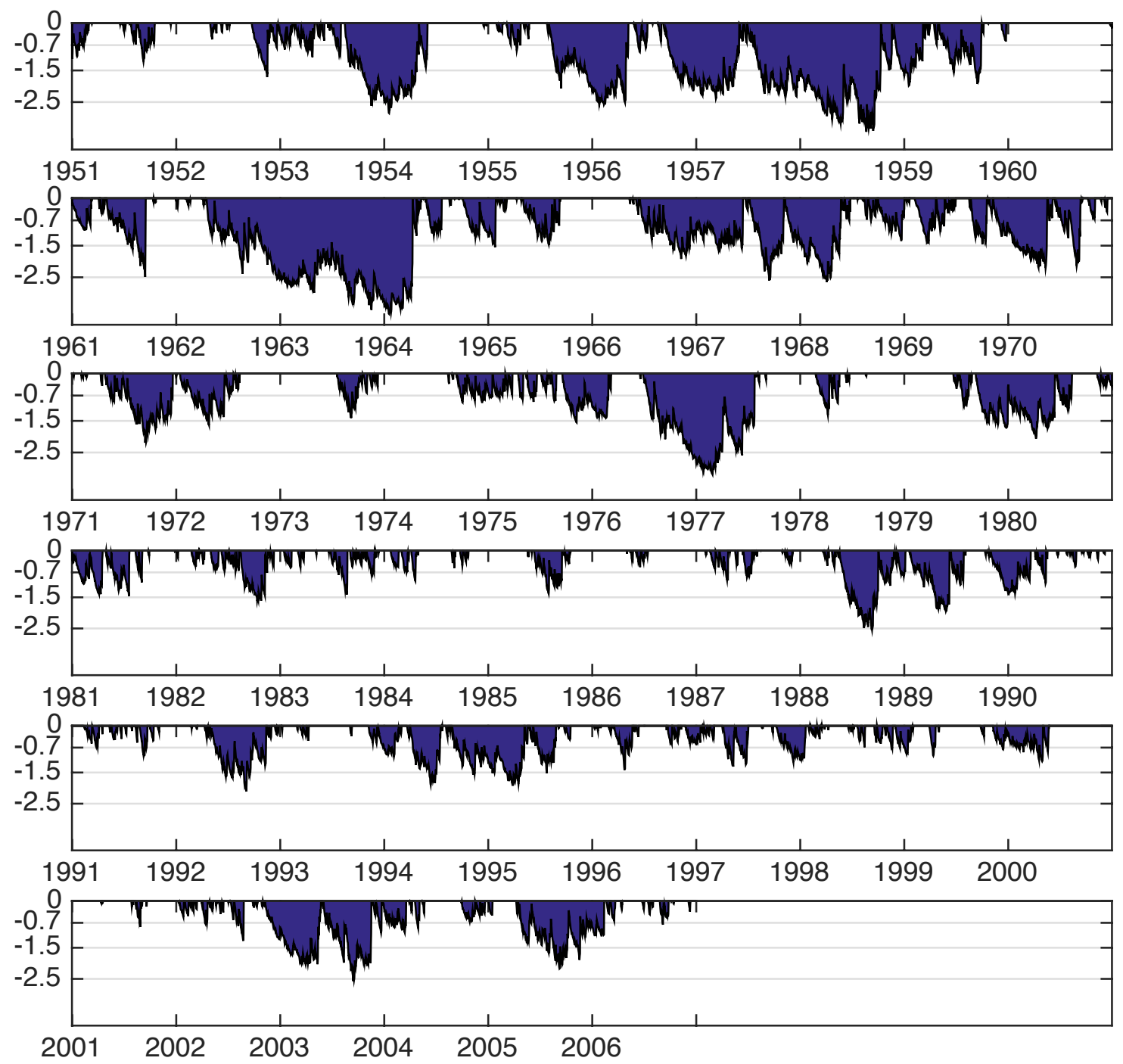

Fig 7 Daily Effective Drought Index for the Milwaukee South catchment 

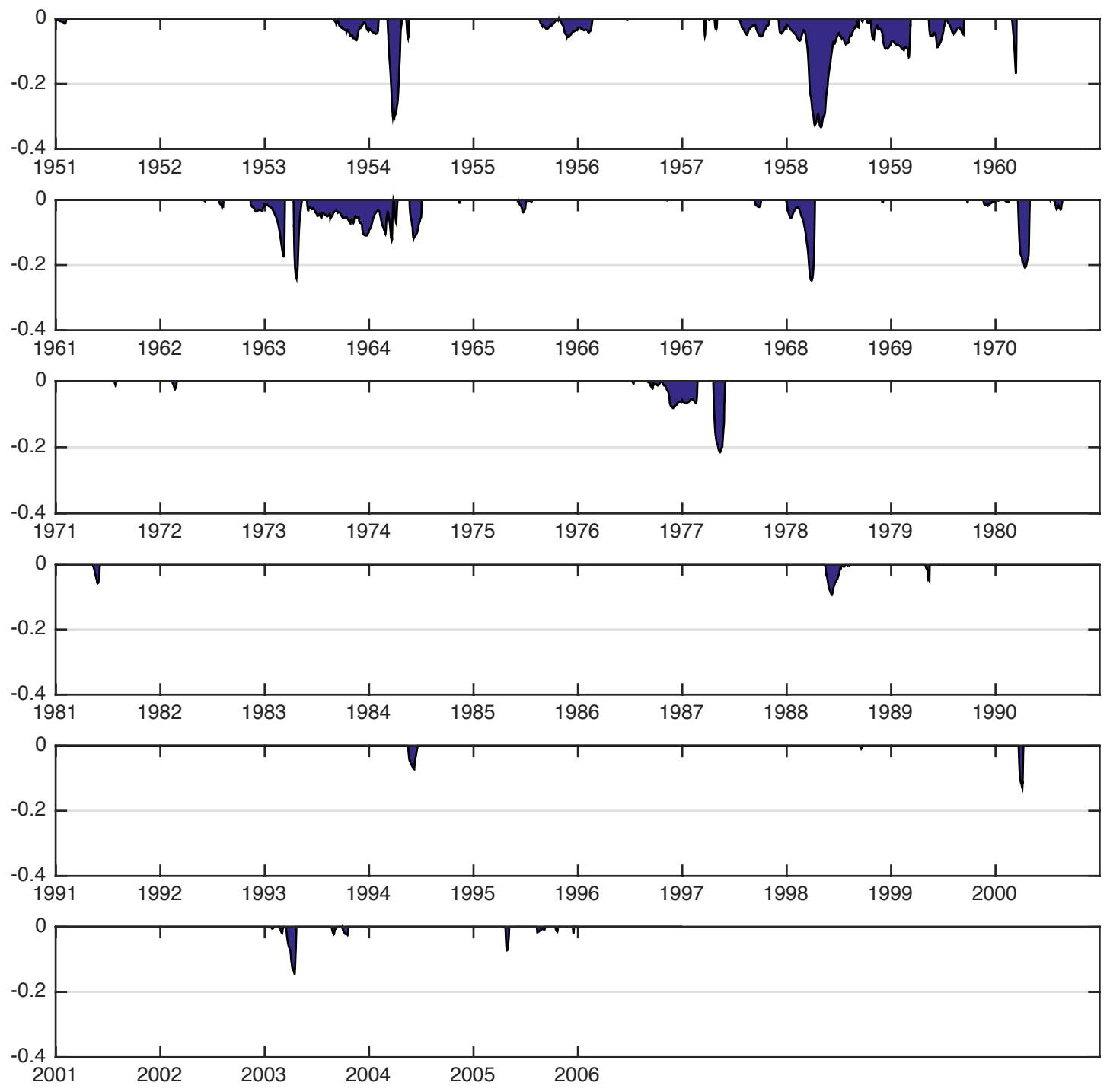

549

550

551
Fig 8 Daily streamflow deficit (mm) for the Milwaukee River streamflow measurement site 

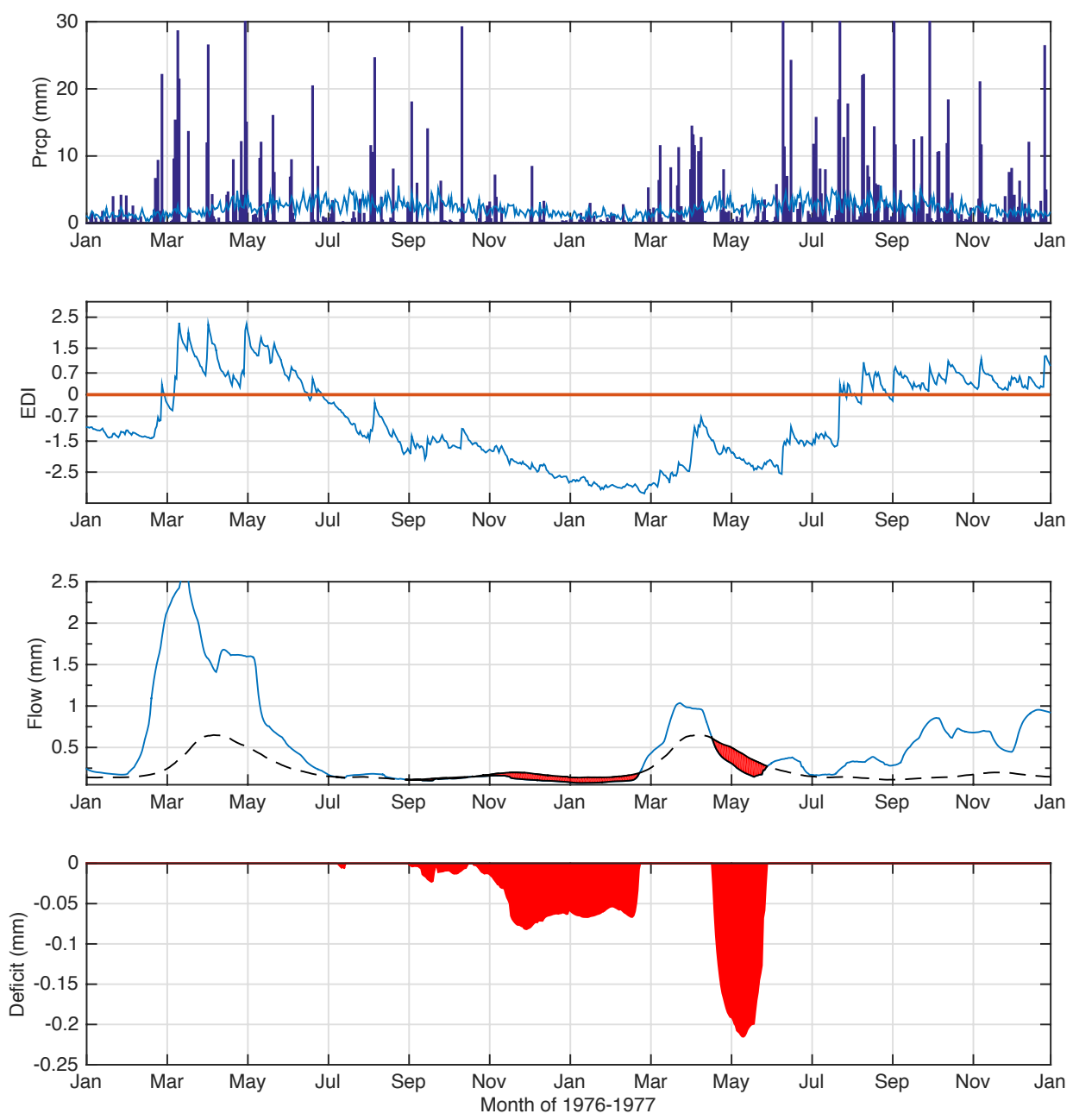

Fig 9 Drought propagation in the Milwaukee River basin for the years 1976-1977. Top panel: daily precipitation during 1976-1977 (bars) and mean daily precipitation for the 555 record period (line). The y-axis is truncated. Second panel: Effective Drought Index.

556 Third panel: smoothed daily streamflow (solid line) and the streamflow drought threshold 557 (dashed line). Bottom panel: streamflow deficit. 